\title{
Sistem Pendukung Keputusan Penerimaan Karyawan Menggunakan Metode Simple Multi-Attribute Rating Technique (SMART)
}

\author{
Sri Nurhayati ${ }^{\mathrm{a} 1}$, Riani Lubis ${ }^{\mathrm{b} 2}$ \\ ${ }^{a}$ Program Studi Sistem Komputer Universitas Komputer Indonesia ${ }^{l}$ \\ Jl. DIpati Ukur No. 102 - 116 Bandung 40132 \\ ${ }^{1}$ sri.nurhayati@email.unikom.ac.id \\ Program Studi Teknik Informatika Universitas Komputer Indonesia ${ }^{1}$ \\ Jl. DIpati Ukur No. 102 - 116 Bandung 40132 \\ 2riani.lubis@email.unikom.ac.id
}

\begin{abstract}
Abstrak
Seiring dengan perkembangan teknologi informasi yang semakin pesat menuntut segala pekerjaan harus dilakukan dengan cepat pula. Hampir setiap perusahaan menggunakan teknologi informasi untuk menunjang pekerjaannya, salah satunya dalam proses penerimaan karyawan. Proses penerimaan karyawan memerlukan cara yang professional dan akurat agar menghasilkan karyawan yang dapat mendukung mutu dan kesuksesan sebuah perusahaan. Dikarenakan prose penerimaan karyawan merupakan hal yang sangat penting di sebuah persahaan, maka dibutuhkan system pendukung keputusan yang akan memutuskan calon karyawan mana yang akan diterima. Data yang digunakan pada penelitian ini adalah data karyawan pada salah satu peusahaan di daerah Bandung Jawa Barat. Tujuan dari penelitian ini adalah memberikan model dan analisis sistem pendukung keputusan penerimaan karyawan sehingga dapat membantu perusahaan dalam memilih calon karyawan yang tepat untuk perusahaannya. Metode yang digunakan dalam penelitian ini adalah metode Simple Multi-Attribute Rating Technique (SMART), metode ini merupakan metode pengambilan keputusan multi kriteria. Kriteria penilaian yang digunakan untuk proses rekrutmen pegawai adalah beberapa kriteria seperti pendidikan, pengalaman kerja, tes, wawancara, usia, dan status. Setelah dilakukan pengujian terhadap data calon karyawan, maka didapat urutan ranking nilai utilitas dari data tersebut, dari urutan tersebut memudahkan perusahaan dalam mengambil keputusan tentang calon karyawan mana yang akan diterima.
\end{abstract}

Kata kunci: Penerimaan Karyawan, Sistem pendukung keputusan, Simple Multi-Attribute Rating Technique (SMART)

\section{Employee Recruitment System in The Trisula Textile Industri Using The Simple Multi-Attribute Rating Technique (SMART) Method}

\begin{abstract}
Along with the rapid development of information technology, all work must be done quickly too. Almost every company uses information technology to support its work, one of which is in the employee recruitment process. Currently, the employee recruitment process at the Trisula Textile Industri company is still not conventional. Related parties from companies that carry out the selection for employee recruitment have difficulty in determining the employees to be accepted, because of the many candidates sometimes do not meet the appropriate qualifications in the company, or even already have the appropriate qualifications but seen from the employee acceptance criteria tend to be the same as other candidates. . The purpose of this study is to create a system that can assist companies in selecting the right prospective employees for the company. The method used in this research is the Simple Multi-Attribute Rating Technique (SMART) method. This method is a multi-criteria decision-making method. The assessment criteria used for the employee recruitment process are several criteria such as education, work experience, age, and status. After testing the data of 10 prospective employees, a ranking order of utility value is obtained from the data. From this sequence, it makes it easier for companies to make decisions about which prospective employees to accept.
\end{abstract}


Keywords: Recruitment, Simple Multi-Attribute Rating Technique (SMART), Multi-criteria

\section{Pendahuluan}

Salah satu bagian penting dalam sebuah perusahaan adalah sumber daya manusia atau karyawan. Karyawan merupakan adalah satu investasi bagi sebuah perusahaan untuk tumbuh kembang sesuai dengan visi misi dan tujuan dari perusahaan [1]. Proses penerimaan karyawan memerlukan cara yang professional dan akurat agar menghasilkan karyawan yang dapat mendukung mutu dan kesuksesan sebuah perusahaan. Pada saat sebuah perusahaan melakuakan proses penerimaan karyawan yang sifatnya subyektif dan konvensional, hal ini tentunya membuat pihak perusahaan mengalami kesulitan pengambilan keputusan untuk menentukan karyawan mana yang akan diterima [2], [3]. Bila proses tersebut dibiarkan dalam waktu yang panjang maka dapat mempengaruhi kinerja dari perusahaan sehingga berakibat perusahaan gagal dalam mencapai tujuannya.

Pengambilan keputusan dalam pemilihan karyawan menjadi hal yang sangat penting bagi perusahaan. Sistem pendukung keputusan merupakan sebuah sistem yang berbasis komputer yang dapat membantu untuk pengambilan keputusan dengan memanfaatkan data yang ada dalam menyelesaikan sebuah permasalahan . Sistem pendukung keputusan juga sistem yang menghasilkan keputusan yang lebih objektif [4]-[6]. Pada penelitian ini metode yang digunakan untuk mendukung keputusan dalam pemilihan karyawan adalah metode Simple MultiAttribute Rating Technique (SMART), metode ini merupakan metode pengambilan keputusan multi kriteria. Teknik pengambilan keputusan multi kriteria ini didasarkan pada teori bahwa setiap alternatif terdiri dari sejumlah kriteria yang memiliki nilai-nilai dan setiap kriteria memiliki bobot yang menggambarkan seberapa penting ia dibandingkan dengan kriteria lain. Pembobotan ini digunakan untuk menilai setiap alternative agar diperoleh alternative terbaik. Kriteria penilaian yang digunakan untuk proses penerimaan pegawai adalah beberapa kriteria seperti pendidikan, pengalaman kerja, tes, wawancara, usia, dan status.

Beberapa penelitian yang terkait dengan system pendukung keputusan yang berhubungan dengan proses penilaian karyawan sudah pernah dilakukan. Pada penelitian sebelumnya sudah ada penelitian pengambilan keputusan untuk menilai kinerja karyawan menggunakan metode analytic Hierarcy Process (AHP), dan menghasilkan bahwa system pengambilan keputusan denan menggunakan metode tersebut sudah memberikan keputusan yang objektif untuk menilai kinerja [7]. Penelitian lain adalah penerapan metode SMART untuk melakukan pengambilan keputusan dari masalah yang ada hasil dari penelitian tersebut menyatakan bahwa metode tersebut dapat digunakan untuk pengambilan keputusan [8]-[10].

Oleh karena itu untuk mengatasi masalah yang ada di perusahaan dalam hal ini adalah proses penerimaan karyawan, maka pada penelitian ini akan dibuat system pendukung keputusan penerimaan karyawan menggunakan metode SMART yang bertujuan untuk menghasilkan model system dan analisis dari metode tersebut sehingga memudahkan pihak perusahaan dalam menentukan karyawan yang akan diterima.

\section{Metodologi}

Tahap pertama dari penelitian ini adalah melakukan pengumpulan data. Pada tahap ini dilakukan melalui wawancara, pengamatan langsung, dan studi pustaka. Wawancara dan pengamatan langsung dilakukan dengan mewawancara dan mengamati langsung kepada pihak terkait di perusahaan bagaimana mengelola proses penerimaan karyawan, dan kriteria pa saja yang digunakan pada proses tersebut. Untuk studi pustaka dilakukan dengan mencari referensi yang terkait dengan penelitian melalui bebrapa sumber, baik dari buku ataupun jurnal jurnal ilmiah.

Tahap kedua adalah menganalisis proses penerimaan karyawan menggunakan metode SMART. Adapun tahapan dari metode ini adalah sebagai berikut [11], [12] :

a. Menentukan kriteria yang akan digunakan.

b. Menentukan nilai bobot dari setiap kriteria, untuk nilai bobot yang digunakan antara 1 - 100 .

c. Menghitung normalisasi dari setiap kriteria, yaitu dengan menggunakan persamaan 1. Dimana $w_{j}$ adalah nilai bobot dari setiap kriteria.

$$
\text { Normalisasi }=\frac{w_{j}}{\sum w_{j}}
$$

d. Memberikan nilai kriteria pada setiap alternatif.

e. Menentukan nilai utility kriteria pada setiap kriteria di setiap alternative menggunakan persamaan 2 .

$$
\begin{aligned}
& u_{i}\left(a_{i}\right)=\frac{w_{\operatorname{man}\left[j^{-t_{i n i n}}\right.}}{c_{\text {max }}-c_{\text {min }}} \\
& \text { Dimana : } \\
& \mathrm{u}_{\mathrm{i}}\left(\mathrm{a}_{\mathrm{i}}\right) \quad \text { : nilai utility dari kriteria } \mathrm{i} \\
& \mathrm{c}_{\text {out(i) }} \quad: \text { nilai kriteria ke-i } \\
& \mathrm{c}_{\min } \quad \text { : nilai minimal kriteria } \\
& \mathrm{c}_{\max } \quad \text { : nilai maksimal kriteria }
\end{aligned}
$$

f. Hitung nilai akhir masing-masing, dengan menggunakan persamaan 3 .

$\operatorname{NA}\left(a_{\mathrm{i}}\right)=\Sigma\left(n k_{\mathrm{i}} * u k_{\mathrm{i}}\right)$

Dimana :

$\mathrm{NA}\left(\mathrm{a}_{\mathrm{i}}\right)$ : nilai akhir dari alternative $\mathrm{i}$

$\mathrm{nk}_{\mathrm{i}} \quad$ : nilai normalisasi kriteria ke-i

$\mathrm{uk}_{\mathrm{i}} \quad$ : nilai utility kriteria ke I pada

alternative $\mathrm{i}$

Tahap akhir adalah membuat model sistem pendukung keputusan penerimaan karyawan menggunakan metode SMART. Pada tahapan ini analisis kebutuhan sistem menggunakan dengan tools Unified Modeling Language (UML). Tools ini berfungsi digunakan untuk pemodelan perangkat lunak dengan pendekatan objek. UML juga dapat dijadikan sebagai blue print dari sebuah system karena sangat lengkap dan detail [13], [14].

\section{HASIL DAN PEMBAHASAN}

Pada bagian ini membahas hasil analisis proses penerimaan karyawan menggunakan metode SMART, dan hasil model system untuk system pendukung keputusan penerimaan karyawan menggunakan metode SMART. 


\section{A. Analisis Proses Penerimaan Karyawan Menggunakan} Metode SMART

Pada penelitian ini kriteria yang digunakan untuk penerimaan karyawan adalah pendidikan, pengalaman kerja, tes, waancara, usia, dan status. Adapun uraian detail dan nilai dari setiap kriteria dapat dilihat pada Tabel I.

TABEL I

BOBOT KRITERIA PEMILIHAN KARYAWAN

\begin{tabular}{|c|c|c|c|}
\hline $\begin{array}{c}\text { No } \\
\text { Kriteria }\end{array}$ & Kriteria & Nilai & Bobot \\
\hline \multirow{4}{*}{ K1 } & \multicolumn{3}{|l|}{ Pendidikan } \\
\hline & S1 & 100 & \multirow{3}{*}{$30 \%$} \\
\hline & D3 & 80 & \\
\hline & SMA / SMK & 60 & \\
\hline \multirow{4}{*}{ K2 } & \multicolumn{3}{|l|}{ Pengalaman Kerja } \\
\hline & > 3 Tahun & 100 & \multirow[t]{3}{*}{$25 \%$} \\
\hline & $1-3$ Tahun & 80 & \\
\hline & $<1$ Tahun & 60 & \\
\hline \multirow{4}{*}{ K3 } & Tes & & \\
\hline & Baik & 100 & \multirow[t]{3}{*}{$20 \%$} \\
\hline & Cukup & 70 & \\
\hline & Buruk & 50 & \\
\hline \multirow{4}{*}{ K4 } & Wawancara & & \multirow{4}{*}{$20 \%$} \\
\hline & Baik & 100 & \\
\hline & Cukup & 70 & \\
\hline & Buruk & 50 & \\
\hline \multirow{3}{*}{ K5 } & Status & & \multirow{3}{*}{$10 \%$} \\
\hline & Belum Menikah & 100 & \\
\hline & Menikah & 80 & \\
\hline \multirow{3}{*}{ K6 } & Umur & & \multirow{3}{*}{$10 \%$} \\
\hline & $<30$ Tahun & 100 & \\
\hline & $\begin{array}{l}30 \text { Tahun }-35 \\
\text { Tahun }\end{array}$ & 80 & \\
\hline
\end{tabular}

Pada penelitian ini proses pemilihan karyawan dilakukan pada 10 data calon karyawan, adapun nilai kriteria dari 10 calon karyawan tersebut dapat dilihat pada Tabel II.

TABEL II

NiLAi Kriteria SETIAP CALON KaryawaN

\begin{tabular}{|c|c|c|c|c|c|c|c|}
\hline No & $\begin{array}{c}\text { Calon } \\
\text { Karyawan }\end{array}$ & K1 & K2 & K3 & K4 & K5 & K6 \\
\hline 1 & CK1 & 60 & 80 & 100 & 70 & 100 & 100 \\
\hline 2 & CK2 & 80 & 60 & 100 & 50 & 100 & 100 \\
\hline 3 & CK3 & 60 & 80 & 70 & 100 & 80 & 100 \\
\hline 4 & CK4 & 60 & 60 & 50 & 70 & 100 & 100 \\
\hline 5 & CK5 & 100 & 80 & 100 & 70 & 100 & 80 \\
\hline 6 & CK6 & 60 & 100 & 70 & 100 & 100 & 100 \\
\hline 7 & CK7 & 60 & 100 & 70 & 50 & 80 & 80 \\
\hline 8 & CK8 & 80 & 80 & 100 & 100 & 100 & 100 \\
\hline 9 & CK9 & 100 & 80 & 70 & 70 & 100 & 100 \\
\hline 10 & CK10 & 80 & 60 & 50 & 70 & 100 & 80 \\
\hline
\end{tabular}

Setelah mendapatkan bobot kriteria yang terdapat pada Tabel 1, maka dihitung nilai normalisasi dari setiap kriteria, adapun nilai normalisasi dari setiap kriteria dapat dilihat pada Tabel III. Adapun untuk menghitung nilai normalisasi dari setiap kritera di Tabel III menggunakan persamaan 4, sebagai contoh akan dihitung normalisasi kriteria K1 maka:

Normalisasi $K 1=\frac{25}{100}=0,25$

TABEL III

NILAI NORMALISASI UNTUK SETIAP KRITERIA

\begin{tabular}{|l|l|l|l|}
\hline No & Kriteria & Bobot $(\mathbf{w j})$ & Normalisasi \\
\hline K1 & Pendidikan & 25 & 0,25 \\
\hline K2 & $\begin{array}{l}\text { Pengalaman } \\
\text { kerja }\end{array}$ & 15 & 0,15 \\
\hline K3 & Tes & 20 & 0,2 \\
\hline K4 & Wawancara & 20 & 0,2 \\
\hline K5 & Usia & 10 & 0,1 \\
\hline K6 & Status & 10 & 0,1 \\
\hline
\end{tabular}

Setelah mendapatkan nilai normalisasi untuk setiap kriteria yang ada di Tabel III maka langkah selanjutnya adalah menghitung nilai utlity dari setiap kriteria untuk setiap calon karyawan. Nilai utility untuk setiap kriteria dapat dilihat pada Tabel IV. Untuk menghitung nilai utility dari setiap kritera di Tabel IV menggunakan persamaan 2, sebagai contoh akan dihitung utility kriteria K1 maka:

Nilai $c_{\min }$ dan $c_{\max }$ dari kriteria $\mathrm{K} 1$ adalah $\mathrm{c}_{\min }=60$, dan $\mathrm{c}_{\max }=100$
a. $\quad u_{1}(C K 1)=\frac{60-60}{100-60}=0$
b. $\quad u_{1}(C K 2)=\frac{80-60}{100-60}=0,5$
c. $u_{1}(C K 3)=\frac{60-60}{100-60}=0$
d. $\quad u_{1}(C K 4)=\frac{60-60}{100-60}=0$
e. $u_{1}(C K 5)=\frac{100-60}{100-60}=1$
f. $\quad u_{1}(C K 6)=\frac{60-60}{100-60}=0$
g. $\quad u_{1}(C K 7)=\frac{60-60}{100-60}=0$
h. $u_{1}(C K 8)=\frac{80-60}{100-60}=0,5$
i. $\quad u_{1}(C K 9)=\frac{100-60}{100-60}=1$
j. $\quad u_{1}(C K 10)=\frac{80-60}{100-60}=0,5$
TABEL IV

NILAI UTILITY UNTUK SETIAP KRITERIA

\begin{tabular}{|l|l|l|l|l|l|l|l|}
\hline No & $\begin{array}{c}\text { Calon } \\
\text { Karyawan }\end{array}$ & UK1 & UK2 & UK3 & UK4 & UK5 & UK6 \\
\hline 1 & CK1 & 0 & 0,5 & 1 & 0,4 & 1 & 1 \\
\hline 2 & CK2 & 0,5 & 0 & 1 & 0 & 1 & 1 \\
\hline 3 & CK3 & 0 & 0,5 & 0,4 & 1 & 0 & 1 \\
\hline 4 & CK4 & 0 & 0 & 0 & 0,4 & 1 & 1 \\
\hline 5 & CK5 & 1 & 0,5 & 1 & 0,4 & 1 & 0 \\
\hline 6 & CK6 & 0 & 1 & 0,4 & 1 & 1 & 1 \\
\hline 7 & CK7 & 0 & 1 & 0,4 & 0 & 0 & 0 \\
\hline 8 & CK8 & 0,5 & 0,5 & 1 & 1 & 1 & 1 \\
\hline 9 & CK9 & 1 & 0,5 & 0,4 & 0,4 & 1 & 1 \\
\hline 10 & CK10 & 0,5 & 0 & 0 & 0,4 & 1 & 0 \\
\hline
\end{tabular}


Proses terakhir dari peritungan menggunakan metode SMARt adalah menghitung nilai akhir yang digunakan untuk memutuskan calon karyawan mana saja yang akan diterima, adapun hasil nilai akhir dari perhitungan dapat dilihat pada Tabel V. Cara menghitung nilai akhir adalah menggunakan persamaan 3, sebagai contoh menghitung nilai akhir dari calon karywan 1 CK1 maka :

$$
\begin{gathered}
\mathrm{CK} 1=(0,25 * 0)+(0,15 * 0,5)+(0,2 * 1)+(0,2 * 0,4) \\
+(0,1 * 1)+(0,1 * 1)=0,555 \\
\text { TABEL V } \\
\text { NILAI AKHIR DARI SETIAP KARYAWAN }
\end{gathered}
$$

\begin{tabular}{|l|l|l|l|}
\hline No & $\begin{array}{l}\text { Calon } \\
\text { Karyawan }\end{array}$ & NA & Rangking \\
\hline 1 & CK1 & 0,555 & 5 \\
\hline 2 & CK2 & 0,525 & 6 \\
\hline 3 & CK3 & 0,455 & 7 \\
\hline 4 & CK4 & 0,28 & 9 \\
\hline 5 & CK5 & 0,705 & 2 \\
\hline 6 & CK6 & 0,63 & 4 \\
\hline 7 & CK7 & 0,23 & 10 \\
\hline 8 & CK8 & 0,8 & 1 \\
\hline 9 & CK9 & 0,685 & 3 \\
\hline 10 & CK10 & 0,305 & 8 \\
\hline
\end{tabular}

Berdasarkan Tabel $\mathrm{V}$ perhitungan menggunakan metode SMART maka didapat nilai akhir dari setiap calon karyawan, dan nilai akhir yang tertinggi adalah 0,8 dengan rangking 1 sehingga didapatkan calon karyawan yang terbaik yang dapat diterima.

\section{B. Model Sistem Pendukung Keputusan Penerimaan Karyawan Menggunakan Metode SMART}

Pada bagian ini dibahas model dari sistem pendukung keputusan penerimaan karyawan membantu perusahaan dalam memilih calon karyawan yang tepat untuk perusahaannya. Gambar 1 menunjukkan bahwa sistem pendukung keputusan penerimaan karyawan membutuhkan data calon karyawan seperti pendidikan, pengalaman kerja, tes, wawancara, usia, dan status. Data akan diolah untuk memberikan informasi pengambilan keputusan penerimaan karyawan. Metode yang digunakan untuk oleh data tersebut menggunakan metode SMART.

Perancangan fungsional sistem pendukung keputusan perencanaan penerimaan karyawan digambarkan menggunakan usecase.

Rancangan fungsional dari system yang dibuat dapat dilihat pada gambar 2. Gambar 2 merupakan usecase dari system yang akan dibuat, dimana usecase merupakan aktivitas yang dilakukan actor atau pengguna terhadap system [14] [15]. Gambar 2 menunjukan bahwa pengguna dari system adalah pihak dari perusahaan yang terkait dengan proses penerimaan karyawan (HRD) dan operator data. Deskripsi dari setiap usecase yang ada di Gambar 1 .

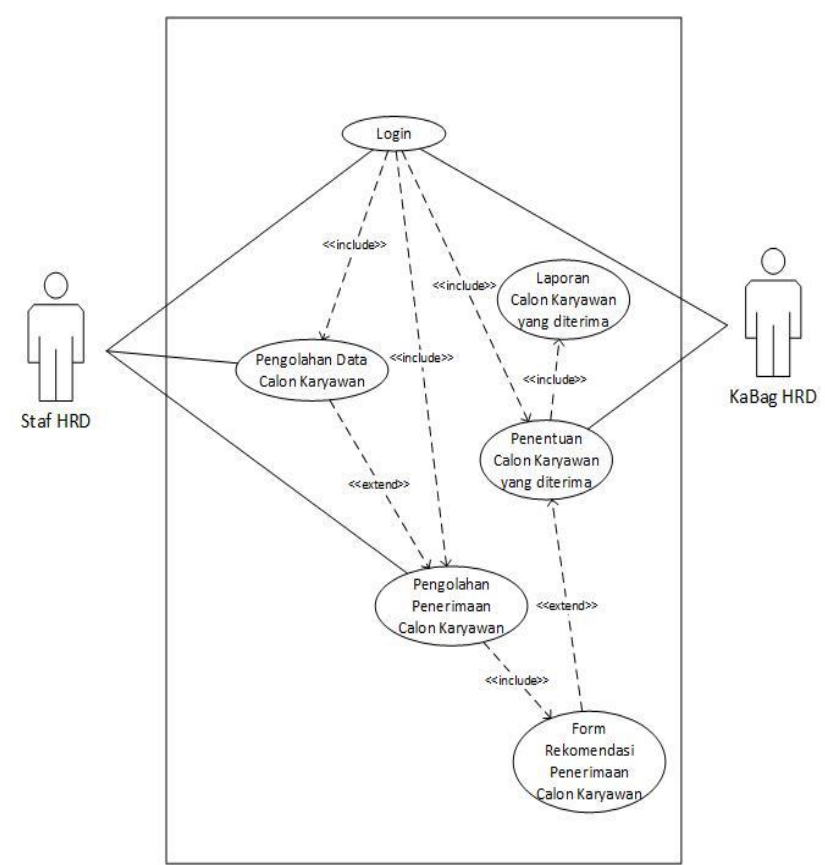

Gambar 1. Usecase sistem pendukung keputusan penerimaan karyawan

Gambar 1 menunjukkan bahwa terdapat dua pengguna sistem pendukung keputusan penerimaan karyawan yang dibangun. Setiap pengguna tersebut dapat menjalankan beberapa fungsional yang berbeda satu dengan yang lainnya. Tabel VI berikut ini akan menjelaskan lebih detil berkaitan dengan fungsional yang terdapat pada sistem pendukung keputusan penerimaan karyawan yang dibangun.

\begin{tabular}{|c|c|c|}
\hline Pengguna & Fungsional & Keterangan \\
\hline \multirow[t]{3}{*}{ Staf HRD } & $\begin{array}{l}\text { Pengolahan data } \\
\text { calon karyawan }\end{array}$ & $\begin{array}{l}\text { Pengguna dapat } \\
\text { melakukan } \\
\text { pengolahan data } \\
\text { calon karyawan } \\
\text { seperti data } \\
\text { identitas, pendidikan } \\
\text { terakhir, } \\
\text { pengalaman bekerja, } \\
\text { hasil tes tulis, serta } \\
\text { data hasil } \\
\text { wawancara }\end{array}$ \\
\hline & $\begin{array}{l}\text { Pengolahan } \\
\text { penerimaan calon } \\
\text { karyawan }\end{array}$ & $\begin{array}{l}\text { Pengguna dapat } \\
\text { melakukan } \\
\text { pengolahan data } \\
\text { penerimaan calon } \\
\text { karyawan dengan } \\
\text { metode SMART. } \\
\text { Pengguna } \\
\text { melakukan } \\
\text { pengolahan kriteria } \\
\text { dan bobotnya } \\
\text { masing-masing, } \\
\text { serta melakukan } \\
\text { proses pergitungan } \\
\text { sehingga diperoleh } \\
\text { hasil nilai akhir. }\end{array}$ \\
\hline & $\begin{array}{l}\text { Form rekomendasi } \\
\text { penerimaan calon } \\
\text { karyawan }\end{array}$ & $\begin{array}{l}\text { Berdasarkan hasil } \\
\text { pengolahan } \\
\text { penerimaan calon } \\
\text { karyawan, pengguna }\end{array}$ \\
\hline
\end{tabular}

TABEL VI

FUNGSIONAL SISTEM PENDUKUNG KEPUTUSAN PENERIMAAN KARYAWAN 


\begin{tabular}{|c|c|c|}
\hline & & $\begin{array}{l}\text { dapat membuat form } \\
\text { rekomendasi calon } \\
\text { karyawan yang akan } \\
\text { di terima kepada } \\
\text { Kabag HRD }\end{array}$ \\
\hline Pengguna & Fungsional & Keterangan \\
\hline \multirow[t]{2}{*}{$\begin{array}{l}\text { Kepala Bagian HRD } \\
\text { (Kabag HRD) }\end{array}$} & $\begin{array}{l}\text { Penentuan calon } \\
\text { karyawan yang } \\
\text { diterima }\end{array}$ & $\begin{array}{l}\text { Berdasarkan form } \\
\text { rekomendasi } \\
\text { penerimaan calon } \\
\text { karyawan, pengguna } \\
\text { (Kabag HRD) dapat } \\
\text { menentukan calon } \\
\text { karyawan yang akan } \\
\text { diterima sesuai } \\
\text { dengan kebutuhan } \\
\text { perusahaan }\end{array}$ \\
\hline & $\begin{array}{l}\text { Laporan calon } \\
\text { karyawan yang } \\
\text { diterima }\end{array}$ & $\begin{array}{l}\text { Pengguna dapat } \\
\text { membuat laporan } \\
\text { tentang calon } \\
\text { karyawan yang } \\
\text { diterima yang akan } \\
\text { diajukan untuk } \\
\text { disahkan oleh } \\
\text { pimpinan } \\
\text { perusahaan. }\end{array}$ \\
\hline
\end{tabular}

\section{KESIMPULAN}

Berdasarkan pemaparan sebelumnya diketahui bahwa metode SMART dapat digunakan untuk menentukan karyawan yang akan diterima berdasarkan beberapa kriteria yang telah ditentukan sebelumnya oleh pihak perusahaan. Oleh karena itu, metode SMART tersebut diimplementasikan pada sistem pengambilan keputusan penerimaan karyawan, sehingga dapat memudahkan perusahaan dalam penentuan karyawan yang akan diterima.

\section{DAFTAR PUSTAKA}

[1] I. Lestiani, "Hubungan Penerimaan Diri Dan Kebahagiaan Pada Karyawan," J. Ilm. Psikol. Gunadarma, vol. 9, no. 2, p. $100173,2016$.

[2] S. Komputer and J. Kuswanto, "Penerimaan Karyawan Baru Menggunakan Metode Profile Matching," vol. 15, no. 2, pp. 85-97, 2020.

[3] O. Fajarianto, M. Iqbal, and J. T. Cahya, "Sistem Penunjang Keputusan Seleksi Penerimaan Karyawan Dengan Metode Weighted Product," J. Sisfotek Glob., vol. 7, no. 1, pp. 49-55, 2017.

[4] T. Ndruru and F. Riandari, "Decision Support System Feasibility Lending At KSU Mitra Karya Cooperative Customer Unit XXVIII with Analytical Hierarchy Process Method," J. Mantik, vol. 3, no. 3, pp. 119-125, 2019.

[5] S. Barus, V. M. Sitorus, D. Napitupulu, M. Mesran, and S. Supiyandi, "Sistem Pendukung Keputusan Pengangkatan Guru Tetap Menerapkan Metode Weight Aggregated Sum Product Assesment (WASPAS)," J. Media Inform. Budidarma, vol. 2, no. 2, pp. 10-15, 2018.

[6] N. W. Al-Hafiz, Mesran, and Suginam, "Sistem Pendukung Keputusan Penentukan Kredit Pemilikan Rumah Menerapkan Multi-Objective Optimization on the Basis of Ratio Analysis ( Moora )," KOMIK (Konferensi Nas. Teknol. Inf. dan Komputer), vol. I, no. 1, pp. 306-309, 2017.

[7] S. Nurhayati, "SISTEM PENILAIAN KINERJA KARYAWAN MENGGUNAKAN METODE TOPSIS PADA PT XYZ," in Saintiks Unikom Bandung, 2017.

[8] Y. Purnamasari, T. H. Pudjiantoro, and D. Nursantika, "Sistem Penilaian Kinerja Dosen Teladan Menggunakan Metode Simple Multy Attribute Rating Technique (Smart)," J. Teknol. Elektro, vol. 8, no. 1, 2017.

[9] S. R. Andani, "Penerapan Metode SMART dalam Pengambilan Keputusan Penerima Beasiswa Yayasan AMIK Tunas Bangsa," J. Sist. dan Teknol. Inf., vol. 7, no. 3, p. 166,
2019.

[10] Y. Sulviyana, A. Tejawati, and U. Hairah, "Sistem Pendukung Keputusan Seleksi Penerimaan Calon Asisten Praktikum Menggunakan Metode SMART," Pros. Semin. Ilmu Komput. dan Teknol. Inf., vol. Vol.2,No.2, no. (September, E-ISSN: 2540-7902-ISSN: 2541-366X), pp. 47-51, 2017.

[11] C. Slamet, F. M. Maliki, U. Syaripudin, A. S. Amin, and M. A. Ramdhani, "Thesis topic recommendation using simple multi attribute rating technique," J. Phys. Conf. Ser., vol. 1402, no. 6 , 2019.

[12] D. Siregar, D. Arisandi, A. Usman, D. Irwan, and R. Rahim, "Research of Simple Multi-Attribute Rating Technique for Decision Support," J. Phys. Conf. Ser., vol. 930, no. 1, 2017.

[13] R. Misra, C. R. Panigrahi, B. Panda, and B. Pati, "Software design," in Application Development and Design: Concepts, Methodologies, Tools, and Applications, 2017.

[14] Suendri, "Implementasi Diagram UML (Unified Modelling Language) Pada Perancangan Sistem Informasi Remunerasi Dosen Dengan Database Oracle (Studi Kasus: UIN Sumatera Utara Medan)," J. Ilmu Komput. dan Inform., vol. 3, no. 1, 2018.

[15] S. K. Shrivastav, B. Hazela, and ScheenuRizvi, "Generating UML Diagram Using Natural Language Processing And Use Case Diagram," IOSR J. Comput. Eng., vol. 20, no. 3, 2018. 